\title{
Milk and dairy food consumption; a comparison between children and adolescents
}

\author{
B. P Green, L. A Turner, J. Bryans, E. Stevenson and P. L. S Rumbold \\ Department of Sport, Exercise and Rehabilitation, Faculty of Health and Life Sciences, Northumbria University, \\ Northumberland Building, Newcastle upon Tyne NE1 8ST, UK
}

Adolescence is a transitional phase between childhood and adulthood (13-19 y) characterised by marked physical development, growing independence and changes toward dietary habits ${ }^{(1)}$ that may ultimately persist into adulthood ${ }^{(2)}$. National dietary surveys typically rely on estimated data collection methods and have shown a decline in dairy consumption with increasing age ${ }^{(3)}$. Yet, the broad age range (4-10 y; 11-18 y) categories make it difficult to differentiate between consumption in children and adolescents. Consequently, there is a need to assess dairy consumption in children and adolescents, using more finite age boundaries and more robust dietary assessment tools. Therefore, the aim of the present study was to compare habitual dairy intake of $9-11 \mathrm{y}$ children $[n=40$; mass $33.5(7.46 \mathrm{~kg})$; BMI $\left.16 \cdot 8\left(3 \cdot 1 \mathrm{~kg} / \mathrm{m}^{2}\right)\right]$ and $15-18 \mathrm{y}$ adolescents $\left[n=35\right.$; mass $66 \cdot 2(15 \cdot 1 \mathrm{~kg})$; BMI $\left.22 \cdot 6\left(3 \cdot 5 \mathrm{~kg} / \mathrm{m}^{2}\right)\right] \mathrm{using}$ these methods. Subsequently, dietary data was assessed using a combined self-report weighed food record and $24 \mathrm{~h}$ dietary recalls, over four consecutive days, (two weekdays and two weekend days). Self-reported dietary habits were extrapolated to determine habitual dairy food consumption (types, amounts and frequencies) and was analysed for differences using a between-group $2 \times 2$ (age $\mathrm{x}$ sex) ANOVA (table 1).

Table 1. Values are presented according to age and sex and displayed as means [SD].

\begin{tabular}{|c|c|c|c|c|}
\hline \multirow[b]{2}{*}{ Dairy food } & \multicolumn{2}{|l|}{ Boys } & \multicolumn{2}{|l|}{ Girls } \\
\hline & $9-11 \mathrm{y}$ & $15-18 \mathrm{y}$ & $9-11 \mathrm{y}$ & $15-18 \mathrm{y}$ \\
\hline Total milk (mL) & 716 [516.8] & $573.4[451.6]$ & $392.6[300]$ & $389 \cdot 3[384.5]$ \\
\hline Daily portions & $1 \cdot 2[0 \cdot 9]$ & $1 \cdot 0[0 \cdot 8]$ & $0.7[0 \cdot 5]$ & $0 \cdot 6[0 \cdot 6]$ \\
\hline Total cheese $(\mathrm{g})$ & $49 \cdot 3$ [34.6] & $35.4[32 \cdot 2]$ & $30 \cdot 3[35]$ & $26 \cdot 4[39 \cdot 8]$ \\
\hline Daily portions & $0.5[0 \cdot 4]$ & $0 \cdot 4[0 \cdot 3]$ & $0 \cdot 3[0 \cdot 4]$ & $0 \cdot 3[0 \cdot 4]$ \\
\hline Total yogurt (g) & $153.8[154.9]$ & $69 \cdot 6[136 \cdot 7]$ & 105 [134] & $123 \cdot 7[225 \cdot 1]$ \\
\hline Daily portions & $0 \cdot 3[0 \cdot 3]$ & $0 \cdot 1[0 \cdot 3]$ & $0 \cdot 2[0 \cdot 3]$ & $0.3[0 \cdot 5]$ \\
\hline Total daily portions & $2.9[1.4]$ & $2 \cdot 1[1 \cdot 2]$ & $2 \cdot 0[1 \cdot 2]$ & $2.0[1 \cdot 0]$ \\
\hline
\end{tabular}

Descriptive data suggested that milk was the most popular dairy product consumed by both children and adolescents. Statistical analysis revealed a main effect for sex on total milk $(\mathrm{mL})\left(\mathrm{F}_{1,71}=7 \cdot 07, p=0.010\right)$ and number of daily milk portions $\left(\mathrm{F}_{1,71}=6 \cdot 79\right.$, $p=0.011)$. There was no interaction or main effect for any other variable. These data suggest that independent of age, boys consume greater amounts of milk compared to girls. In contrast to existing evidence ${ }^{(3)}$, the findings of the present study would suggest no difference in dairy consumption between children and adolescents. With the exception of boys (9-11 y), total daily portions of dairy are on the lower boundary of the $2-3$ recommended servings per day ${ }^{(4)}$, providing evidence to support increasing dairy intake in both children and adolescents.

1. Alberga AS, Sigal RJ, Goldfield G, Prud' homme D, Kenny GP (2012) Overweight and obese teenagers: why is adolescence a critical period? Pediatr Obes, 7(4), 261-73.

2. Hallal P, Victora C, Azevedo M, Wells JK (2006) Adolescent Physical Activity and Health. Sports Med, 36(12), 1019-30.

3. Bates B, Lennonx A, Prentice A, Bates C, Swan G. National Diet and Nutrition Survey: Headline results from Years 1,2 and 3 (combined) of the Rolling Programme (2008/2009- 2010/2011). 2012.

4. Da Silva MS, Rudkowska I (2014) Dairy products on metabolic health: Current research and clinical implications. Maturitas, 77(3), 221-8. 